\title{
(Des)Controle digital de comportamento e a proteção ao livre desenvolvimento da personalidade
}

\section{Digital (un)control of behavior and the protection of free development of personality}

\author{
Haide Maria Hupffer ${ }^{\star}$ \\ Universidade Feevale (Novo Hamburgo, Rio Grande do Sul, Brasil) \\ haide@feevale.br \\ http://orcid.org/0000-0002-4965-9258
}

Gabriel Cemin Petry ${ }^{\star \star}$ Universidade Feevale (Novo Hamburgo, Rio Grande do Sul, Brasil) gabrielcpetry96@gmail.com http://orcid.org/0000-0002-2357-1573

Recebido/Received: $20.01 .2021 /$ January $20^{\text {th }}, 2021$

Aprovado/Approved: $27.02 .2021 /$ February $27^{\text {th }}, 2021$

\begin{abstract}
Resumo: 0 artigo discute a utilização de novas tecnologias no controle digital do comportamento humano sob a ótica do direito e da ética, através do método de investigação dedutivo, fundado em ampla bibliografia interdisciplinar e em documentos legais nacionais e internacionais, com o objetivo de examinar os riscos do desenvolvimento e aplicação do controle comportamental digital por meio de algoritmos e as possiblidades de respostas do direito aos problemas e desafios encontrados. Neste sentido, direitos e garantais fundamentais encontram-se em xeque com o controle de comportamento digital, devendo o direito ao livre desenvolvimento da personalidade ser, neste contexto de digitalização do mundo, (re)afirmado e guarnecido pela defesa do direito à autodeterminação informativa.
\end{abstract}

Como citar este artigo/How to cite this article: HUPFFER, Haide Maria; PETRY, Gabriel Cemin. (Des)Controle digital de comportamento e a proteção ao livre desenvolvimento da personalidade. International Journal of Digital Law, Belo Horizonte, ano 2, n. 1, p. 111-132, jan./abr. 2021. DOI: 10.47975/IJDL/1hupffer

* Docente da Universidade Feevale (Novo Hamburgo, Rio Grande do Sul, Brasil). Pesquisadora no Programa de Pós-Graduação em Qualidade Ambiental e no Curso de Direito da Universidade Feevale. Realizou estágio de Pós-Doutorado em Direito pela Unisinos. Doutora e Mestra em Direito pela Unisinos. Líder do Grupo de Pesquisa CNPq/Feevale "Direito e Desenvolvimento". Líder do Projeto de Pesquisa "Novas Tecnologias e Sociedade de Risco".

** Graduando em Direito e Bolsista de Iniciação Científica na Universidade Feevale (Novo Hamburgo, Rio Grande do Sul, Brasil). 
Palavras-chave: Direito digital. Controle comportamental. Direitos fundamentais. Proteção de dados pessoais.

\begin{abstract}
The article aimed to discuss the use of new technologies in the digital control of human behavior under the perspective of law and ethics, through the deductive investigation method, founded on a wide interdisciplinary bibliography and national and international legal documents, to examine the risks the development and application of digital behavioral control through algorithms and the possibilities of legal responses to problems and challenges encountered. In this way, fundamental rights and guarantees are undermined by the control of digital behavior, and the right to the free development of the personality should, in this context of digitalization of the world, be (re) affirmed and assisted by the defense of the right to informative self-determination.
\end{abstract}

Keywords: Digital law. Behavioral control. Fundamental rights. Personal data protection.

Sumário: 1 Introdução - 2 Novas tecnologias e novas formas de controle: a prática de controle digital comportamental e o valor dos dados pessoais para mecanismos de profiling e behavioral targeting - $\mathbf{3}$ A (re)afirmação do direito ao livre desenvolvimento da personalidade frente ao controle comportamental e riscos à liberdade digital - 4 Conclusão - Referências

\title{
1 Introdução
}

O ser humano do início do século XXI delegou à tecnologia seus dados pessoais e informações de seus movimentos e ações que realiza no ciberespaço. Tudo pode ser mapeado, vigiado e monitorado gerando um grande fluxo de informações sem fronteiras, interconectadas às redes de dispositivos digitais que estão interligados no planeta. Os passos no mundo físico e virtual, as diferentes interações nas redes sociais, filmes, séries e programas assistidos, pesquisas realizadas na internet, compras de produtos e serviços, transações bancárias, viagens, relações no trabalho, preferências políticas, dados sensíveis, aptidões, interações familiares, registros médicos, interesses, reações, movimentos dos olhos e expressões do corpo físico constituem dados de valor inestimável para grandes corporações e governos.

Nas suas interações diárias o ser humano alimenta a sociedade de controle que capta seus movimentos, decodificando-os e depois os converte em um sinal digital analisado por diferentes sistemas de inteligência artificial. De posse das informações, surge a possibilidade de grandes corporações e Estados controlarem as escolhas e os movimentos individuais e coletivos para direcionar informações com objetivo de induzir comportamentos, ações, simpatias e extremismos. Assim, moldados ao controle dos seus criadores e patrocinadores, o "maravilhoso" mundo digital com seus algoritmos vai conduzindo o ser humano como marionetes que se sujeitam e se subordinam a biopolítica da sociedade de controle. Os sistemas de vigilância e controle se transformam em uma ameaça pela coletivização de adequação de comportamentos e produção de subjetividade.

A partir do exposto, o presente estudo objetiva problematizar e discutir à luz do direito e da ética se as novas tecnologias de direcionamento e controle digital 
do comportamento violam o princípio do livre desenvolvimento da personalidade e o direito do ser humano de preservar a sua essência, individualidade, privacidade, dignidade e de tomar decisões com liberdade e autonomia.

O desenvolvimento do conteúdo do artigo está estruturado no método dedutivo amparado em ampla pesquisa bibliográfica interdisciplinar e em documentos legais nacionais e internacionais. O estudo está dividido em duas partes: i) Novas tecnologias e novas formas de controle: a prática de controle digital comportamental e o valor dos dados pessoais para mecanismos de profiling e behavioral targeting; ii) A (re)afirmação do direito ao livre desenvolvimento da personalidade frente ao controle comportamental e riscos à liberdade digital.

A intenção não é criticar os avanços das tecnologias da informação, mas refletir sobre os riscos da manipulação indevida dos dados e das informações pessoais que se encontram em xeque com o controle do comportamento digital por corporações e governos. O livre desenvolvimento da personalidade é o fio condutor do estudo e pretende-se interrogar como as novas formas de controle e vigilância digital têm o poder de induzir comportamentos individuais e coletivos. Heidegger contribui ao indicar que é preciso questionar a técnica e o que se delegou para a técnica para garantir os direitos fundamentais e preservar a autodeterminação informativa, o livre desenvolvimento da personalidade e a essência do que se entende por ser humano.

\section{Novas tecnologias e novas formas de controle: a prática de controle digital comportamental e o valor dos dados pessoais para mecanismos de profiling e behavioral targeting}

Os avanços desenfreados das novas tecnologias no campo digital colocam em xeque as velhas perspectivas não somente no campo da ética e do Direito, mas de toda a sociedade, implicando em uma verdadeira metamorfose do mundo, onde "velhas certezas da humanidade estão desaparecendo e algo totalmente novo emerge". ${ }^{1}$ Fronteiras são dissolvidas com a internet global, questionando, por exemplo, a jurisdição nacional e os limites do uso da informação; ${ }^{2}$ o corpo humano é metamorfoseado em um corpo virtual ou digital (formando "humanos digitais"), confrontando categorias mais tradicionais de identidade social, coletividade e

BECK, Ulrich. Metamorfose do mundo: novos conceitos para uma nova realidade. Tradução de Maria Luiza X. de A. Borges. Rio de Janeiro: Zahar, 2018, p. 15.

2 BOFF, Salete Oro; FORTES, Vinicius Borges; FREITAS, Cinthia Obladen de Almendra. Proteção de dados e privacidade: do direito às novas tecnologias na sociedade da informação. Rio de Janeiro: Lumen Juris, 2018, p. 32 
individualização; “"Mnémosyne”, deusa grega da memória, encontra-se ameaçada de morte pela permanência das informações em rede, sendo necessária a implantação do "direito ao esquecimento digital", ${ }^{4}$ emerge da fusão do mundo on-line e off-line o mundo on-life: onde sistemas computacionais podem "libertar" as pessoas da tomada de decisões humanas, substituindo-as conforme o seu entendimento e influenciando diretamente no comportamento decisório humano, transformando as pessoas cada vez mais em inconscientes digitais (Digital Unconscious). ${ }^{5}$

Algumas inovações, sob aspecto técnico, podem ser mencionadas, tais como: I) utilização de sistemas de inteligência artificial (IA) em aparelhos celulares (smartphones), casas (smart homes), jogos, centrais telefônicas, redes sociais e serviços de atendimento ao consumidor; ii) aplicações de IA no setor automotivo, através de carros autônomos e abrindo espaço para tendências em demais veículos de transporte, como ônibus, táxis e também em aplicativos que trabalham com caronas; ${ }^{6}$ iii) o emprego pelo setor militar de armas autônomas, as denominadas Lethal Autonomous Weapon Systems, que são capazes de detectar e identificar alvos, bem como atacá-los e destruí-los sem intervenção humana; ${ }^{7}$ iv) a implementação de recursos digitais, bem como de novas tecnologias da informação e comunicação (TICs) na automação de cidades (Smart Cities), como consta o exemplo da Cidade Digital de Barcelona, na Espanha; ${ }^{8}$ v) além de contribuição das novas tecnologias, em seu sentido amplo, nos mais variados campos do conhecimento, como no campo da medicina por exemplo, é possível observar novos impactos no campo do Direito, de forma direta no Poder Judiciário e inclusive em processos decisórios ou avaliativos, através de "robôs-classificadores" (que encontram materiais e os classificam), "robôs-relatores" (extração e condensação de informações relevantes de documentos) e "robôs-julgadores" (que produzem, em tese, decisões com base nas informações coletadas). ${ }^{9}$ Deste último ponto, segundo o Conselho Nacional de Justiça brasileiro, existem mais de 40 projetos de implantação de sistemas de IA

3 BECK, Ulrich. Metamorfose do mundo: novos conceitos para uma nova realidade. Tradução de Maria Luiza X. de A. Borges. Rio de Janeiro: Zahar, 2018, p. 190.

4 RODOTÀ, Stefano. A vida na sociedade da vigilância: privacidade hoje. Rio de Janeiro: Renovar, 2008, p. 84 e 269.

5 HOFFMANN-RIEM, Wolfgang. Teoria geral do direito digital: transformação digital: desafios para o Direito. Rio de Janeiro: Forense, 2021, p. 24-26.

6 CHELIGA, Vinicius; TEIXEIRA, Tarcísio. Inteligência Artificial: aspectos jurídicos. Salvador: JusPodivm, 2019, p. 19-21.

7 Ver sobre Lethal Autonomous Weapon Systems em: HUPFFER, Haide Maria; PETRY, Gabriel Cemin. A (im) possibilidade do uso de Lethal Autonomous Weapon System frente ao direito internacional humanitário e a ética. Revista Brasileira de Estudos de Defesa. v. 6, n. 2, p.125-153, jul./dez. 2019, p. 125-129. Disponivel em: https://rbed.abedef.org/rbed/article/view/75153. Acesso em: 22 jan. 2021.

8 MOROZOV, Evgeny; BRIA, Francesca. A Cidade Inteligente: tecnologias urbanas e democracia. Tradução de Humberto do Amaral. São Paulo: Ubu, 2019, p. 96.

9 BOEING, D. H. A.; MORAIS DA ROSA, Alexandre. Ensinando um robô a julgar. pragmática, discricionariedade, heurísticas e vieses no uso de aprendizado de máquinas no judiciário. Florianópolis: Emais Academia, 2020, p. 95-104. 
em 32 tribunais do Brasil, entre eles o Supremo Tribunal Federal, com Victor, e o Superior Tribunal de Justiça, com Sócrates. ${ }^{10}$

Este panorama compõe o rol de inovações que se enquadram no que Wolfgang Hoffmann-Riem denomina de "processo de digitalização" das áreas da vida, tais como as comunicações públicas e privadas, a economia, a cultura e a política. Este processo de digitalização não trata somente das infraestruturas de software e hardware atualmente desenvolvidas e aplicadas, mas também dos impactos representados pela mudança nas condições de vida decorrentes da utilização das novas tecnologias em todo o mundo: fator responsável por reformular as relações de influência e poder. ${ }^{11}$

O Panóptico de Foucault hoje é substituído por um "Panóptico Eletrônico", através do uso de câmeras e sistemas em rede capazes de monitorar cada clique dado e tempo que se passa em determinado lugar ou sitio eletrônico, sendo a informação e o conhecimento sobre a pessoa um pressuposto essencial para eficácia deste método de poder sobre o indivíduo. ${ }^{12}$ Com a computação ubíqua, aparelhos eletrônicos encontram-se por toda parte de forma constante, bem como desenvolvem as mais variadas funções na vida humana, de forma que esta forma de vigilância se torna mais intensa e os "olhos eletrônicos" persistem insaciáveis por mais informações e dados do indivíduo. ${ }^{13}$

Neste aspecto salta um dos produtos deste processo de digitalização: os dados pessoais digitais. Segundo a General Data Protection Regulation (GDPR) europeia, dados pessoais podem ser definidos qualquer informação relativa a uma pessoa singular identificada ou identificável (art. 4으. ${ }^{14}$ Este sentido legal é replicado em diversas legislações de proteção de dados na América Latina, como é o caso da Ley de Protección de Datos Personales na Argentina (art. 4ํ), ${ }^{15}$ a Ley Sobre Protección de la Vida Privada no Chile (art. $\left.2^{\circ}\right)^{16}$ e, dentre outros exemplos,

10 CONSELHO NACIONAL DE JUSTIÇA. Projetos com Inteligência Artificial no Poder Judiciário. Disponível em: https://paineisanalytics.cnj.jus.br/single/?appid=29d710f7-8d8f-47be-8af8-a9152545b771\&sheet= b8267e5a-1f1f-41a7-90ff-d7a2f4ed34ea\&lang=pt-BR\&opt=ctxmenu,currsel. Acesso em: 06 jan. 2021.

11 HOFFMANN-RIEM, Wolfgang. Teoria geral do direito digital: transformação digital: desafios para o Direito. Rio de Janeiro: Forense, 2021, p. 1-2.

12 RUARO, Regina Linden. Privacidade e autodeterminação informativa: obstáculos ao Estado de Vigilância. Arquivo Jurídico, Teresina, v. 2, n. 1, jan./ jun. de 2015, p. 54. Disponível em: http://revistas.ufpi.br/ index.php/raj. Acesso em: 10 jan. 2021.

13 BOFF, Salete Oro; FORTES, Vinicius Borges; FREITAS, Cinthia Obladen de Almendra. Proteção de dados e privacidade: do direito às novas tecnologias na sociedade da informação. Rio de Janeiro: Lumen Juris, 2018, p. 26 e 133.

14 UNIÃO EUROPEIA. Regulamento (UE) 2016/679 do Parlamento Europeu e do Conselho de 27 de abril de 2016. Disponivel em: https://eur-lex.europa.eu/legal-content/PT/TXT/PDF/?uri=CELEX:32016R0679\&fr om=pt. Acesso em: 20 dez. 2020.

15 ARGENTINA. Protección de los datos personales. Ley 25.326/2020. Promulgada parcialmente en octubre 30 de 2000. Disponível em: https://www.oas.org/juridico/PDFs/arg_ley25326.pdf. Acesso em: 18 dez. 2020.

16 CHILE. Ley № 19.628 de 18 ag. 1999. Sobre Protección de la vida privada. Disponível em: https://www. leychile.cl/Navegar?idNorma=141599\&buscar=19628. Acesso em: 10 dez. 2020. 
a Lei Geral de Proteção de Dados (LGPD) brasileira, conforme o seu artigo 5ำ, que define dados pessoais como qualquer "informação relacionada a pessoa natural identificada ou identificável". ${ }^{17}$

Ocorre que os dados pessoais são dotados de uma natureza especial, que possibilitam sua viabilidade no mercado como bens econômicos de alta validade, sendo equiparados ao petróleo bruto. Tal equiparação metafórica - entre dados brutos e petróleo bruto - possui certas distinções interessantes para o debate, tais como: i) diferentemente do petróleo e do gás natural, dados são produzidos em segundos de uma forma não limitada; ii) dados não se encontram escondidos pelo mundo, mas, sim, em praticamente qualquer lugar, sendo tecnicamente de fácil armazenamento; iii) existem pequenas e grandes "refinarias" de dados brutos, tais como grandes empresas como Facebook, Google e Amazon, além de órgãos e agências governamentais; iv) os dados brutos, com auxílios de sistemas de IA, podem dar mais qualidade e variedade a produtos derivados da coleta e extração de dados; v) a coleta de dados pode não resultar em um consumo imediato, mas em um momento posterior, aumentando o valor dos dados ou até mesmo implicando na inexatidão e "descarte" dos dados. ${ }^{18}$

Tratam-se, portanto, de bens de informação em um mercado multilateral capaz de conectar atores e campos de atividades distintos, o que é visível, por exemplo, na relação triangular de usuários, mecanismos de busca e anunciantes. Em breve síntese, as tecnologias utilizadas neste processo são empregadas para a coleta de dados comportamentais do usuário, detendo alto valor preditivo, o qual é realizado com base na coleta de dados que representam o comportamento on-line do usuário através do histórico de navegação, buscas em rede e redes sociais. ${ }^{19}$ De pronto, faz-se possível denunciar a contradição da prática de coleta excessiva de dados - que em nada melhoram o funcionamento da aplicação digital - com princípios de finalidade (específica) e necessidade (adequada aos fins do tratamento) esculpidos nos incisos I e III, do artigo 6으, da LGPD. Fora que, por força do §4으, do art. $8^{\circ}$, do referido diploma legal, qualquer coleta de dados com fins genéricos será considerada nula, reconhecendo-se como viciado o consentimento do titular. ${ }^{20}$

A prática de coleta de dados relacionados ao comportamento digital para fins comerciais e publicitários não se trata de uma novidade. Jim Edwards, em outubro de 2012, escreveu o seguinte artigo neste sentido: Apple Has Quietly Started

1 BRASIL. Lei no 13.709, de 14 de agosto de 2018. Lei Geral de Proteção de Dados. Disponível em: http:// www.planalto.gov.br/ccivil_03/_ato2015-2018/2018/lei/L13709.htm. Acesso em: 28 dez. 2020.

18 HOFFMANN-RIEM, Wolfgang. Teoria geral do direito digital: transformação digital: desafios para o Direito. Rio de Janeiro: Forense, 2021, p. 19-21.

19 HOFFMANN-RIEM, Wolfgang. Teoria geral do direito digital: transformação digital: desafios para o Direito. Rio de Janeiro: Forense, 2021, p. 58.

20 BRASIL. Lei no 13.709, de 14 de agosto de 2018. Lei Geral de Proteção de Dados. Disponível em: http:// www.planalto.gov.br/ccivil_03/_ato2015-2018/2018/lei/L13709.htm. Acesso em: 28 dez. 2020. 
Tracking iPhone Users Again, And It's Tricky To Opt Out. Atentava, à época, que se determinado usuário estivesse olhando vários sites de carros no celular, o sistema entenderia que provavelmente o usuário estivesse procurando comprar algum veículo, logo seria bombardeado por anúncios (Ads). Isso ocorria através de um sistema de rastreamento nomeado de Identifier for Advertisers (IFA), previamente habilitado no aparelho celular, que gerava anúncios em aplicativos de aparelhos móveis e na internet, informando ao anunciante que determinado usuário está olhando para uma determinada publicação, servindo assim para um direcionamento (targeting). E mais: a ferramenta é significantemente prática para inferência comportamental humana. ${ }^{21}$

O fenômeno acima referido é nomeado de "online behavioral advertising" (OBA) - em língua portuguesa "publicidade comportamental online". Este processo é também usualmente chamado de "perfilhamento online" (online profiling) ou “direcionamento comportamental" (behavioral targeting) e a aplicação de OBA pode ser definida como "a prática de monitorar o comportamento online das pessoas e usar as informações coletadas para mostrar anúncios direcionados individualmente". ${ }^{22}$

De uma forma mais técnica, muitas vezes o referido direcionamento comportamental é realizado por meio de tracking cookies, dentre outros como as impressões digitais do dispositivo. No caso dos cookies rastreadores, interessa atentar que os mais populares sítios eletrônicos chegam a coletar mais de 6.000 cookies, sendo a maioria destes de sites terceiros que coletam cerca de 350 cookies de rastreamento do usuário. ${ }^{23}$

Neste processo, alguns dos fatores característicos controlados pelos anunciantes são: I) o nível de personalização de anúncios; e ii) precisão dos anúncios. No primeiro caso, o nível de personalização é fundado em (a) dados pessoais para o procedimento de targeting, tais como históricos de busca e pesquisa on-line; e (b) a quantidade de informação utilizada em pesquisas de termos na internet ou histórico de pesquisa, podendo ainda ser utilizada a coleta de dados atinentes a idade, gênero, localização, nível de educação, comportamento em compras on-line, históricos de busca e interesses do usuário. O segundo ponto atine a precisão, que

21 EDWARDS, Jim. Apple Has Quietly Started Tracking iPhone Users Again, And It's Tricky To Opt Out, 2012. Disponivel em: https://www.businessinsider.com/ifa-apples-iphone-tracking-in-ios-6-2012-10. Acesso em: 04 jan. 2021.

22 "The practice of monitoring people's online behavior and using the collected information to show people individually targeted advertisements" (BOERMAN, Sophie C.; KRUIKEMEIER, Sanne; BORGESIUS, Frederik J. Zuiderveen. Online Behavioral Advertising: A Literature Review and Research Agenda. Journal of Advertising, v. 46, n. 3, 2017, p. 364 Disponível em: https://www.tandfonline.com/doi/full/10.1080/00 913367.2017.1339368. Acesso em: 05 jan. 2021).

23 BOERMAN, Sophie C.; KRUIKEMEIER, Sanne; BORGESIUS, Frederik J. Zuiderveen. Online Behavioral Advertising: A Literature Review and Research Agenda. Journal of Advertising, v. 46, n. 3, 2017, p. 364. Disponível em: https://www.tandfonline.com/doi/full/10.1080/00913367.2017.1339368. Acesso em: 05 jan. 2021. 
ocorre quando o usuário se dá conta de que determinado anúncio é baseado no seu comportamento on-line passado, entendendo, assim, que determinado profissional de marketing realizou interferências sobre as suas escolhas de consumo. ${ }^{24}$

Outras práticas de controle comportamental por meio de algoritmos podem ser exemplificadas através de mecanismos como o uso de ferramentas de autocomplete - valendo-se do comportamento posterior do usuário - e o controle do News Feed de diversas plataformas de comunicação, através de fatores de "rankeamento" de posicionamentos e preferências, influenciando diretamente em resultados de busca e atualização. ${ }^{25} \mathrm{O}$ ponto de partida deste tipo de controle inicia-se com a criação de perfis (perfilagem ou profiling): a criação ou caracterização de perfis, segundo a ótica de Boff, Freitas e Fortes, trata-se de um reflexo da prática de tratamento de dados pessoais, tendo como objetivo a indicação do que pode ser relevante para determinados usuários dentro de determinado contexto, verificando se o indivíduo ou o grupo de pessoas próximas ao primeiro podem se interessar acerca de determinado produto. ${ }^{26}$

A criação de perfis é definida pela GDPR, em seu art. 4ํㅜ, como qualquer forma de tratamento automatizado de dados pessoais que avalie aspectos da vida pessoal de pessoas com o fim de "analisar ou prever aspetos relacionados com o seu desempenho profissional, a sua situação económica, saúde, preferências pessoais, interesses, fiabilidade, comportamento, localização ou deslocações". ${ }^{27}$ Entretanto, tem-se que as informações coletadas, ainda que em grandes bancos de dados, tendem a ser parciais, resultando no que Stefano Rodotà chama de "metaconhecimentos" sobre o cidadão, que "dificilmente podem ser verificados pelos interessados, embora até embasem decisões sobre eles". ${ }^{28}$ Quanto a isso, fora algumas exceções, o titular de dados tem garantido o direito de não se sujeitar a decisões individuais automatizadas e inclusive na criação de perfis, conforme dispõe o art. 22, da GDPR - incorporada na LGPD brasileira em seu art. $20 .^{29}$

24 BOERMAN, Sophie C.; KRUIKEMEIER, Sanne; BORGESIUS, Frederik J. Zuiderveen. Online Behavioral Advertising: A Literature Review and Research Agenda. Journal of Advertising, v. 46, n.3, 2017, p. 365-367. Disponível em: https://www.tandfonline.com/doi/full/10.1080/00913367.2017.1339368. Acesso em: 05 jan. 2021.

25 HOFFMANN-RIEM, Wolfgang. Teoria geral do direito digital: transformação digital: desafios para o Direito. Rio de Janeiro: Forense, 2021, p. 62.

26 BOFF, Salete Oro; FORTES, Vinicius Borges; FREITAS, Cinthia Obladen de Almendra. Proteção de dados e privacidade: do direito às novas tecnologias na sociedade da informação. Rio de Janeiro: Lumen Juris, 2018, p. 161.

27 UNIÃO EUROPEIA. Regulamento (UE) 2016/679 do Parlamento Europeu e do Conselho de 27 de abril de 2016. Disponível em: https://eur-lex.europa.eu/legal-content/PT/TXT/PDF/?uri=CELEX:32016R0679\&fr om=pt. Acesso em: 20 dez. 2020.

28 RODOTÀ, Stefano. A vida na sociedade da vigilância: privacidade hoje. Rio de Janeiro: Renovar, $2008, \mathrm{p}$. 115.

29 BRASIL. Lei no 13.709, de 14 de agosto de 2018. Lei Geral de Proteção de Dados. Disponível em: http:// www.planalto.gov.br/ccivil_03/_ato2015-2018/2018/lei/L13709.htm. Acesso em: 28 dez. 2020. 
O procedimento funda-se no uso de algoritmos que avaliam comportamentos anteriores do usuário, procurando estabelecer padrões de comportamento como atitudes e valores, muitas vezes incluindo o usuário, de acordo com seu perfil, em grupos de usuários para realização do behavioral targeting, ou seja, do direcionamento comportamental para publicidade comercial e até mesmo eleitoral (v.g., utilização de bots em processos eleitorais e políticos, como a retirada do Reino Unido do “Brexit” em 2016), com base na filtragem de informações do usuário. No aspecto, pode-se igualmente falar que "o desenvolvimento de valores, o desdobramento de emoções, o processamento de experiências e preferências podem ser influenciados, até mesmo o abandono da curiosidade pelo inesperado". ${ }^{30}$

Importa destacar que a prática de profiling pode, ainda, dar margem à discriminação, colocando a garantia constitucional de igualdade em xeque. Exemplo de discriminação por meio do perfilhamento pode ser vista na aplicação do "Imposto Rosa" (Pink Tax), onde produtos idênticos possuem valores distintos conforme o gênero do usuário consumidor. ${ }^{31}$ As situações de discriminação podem ocorrer em diferentes casos, mas tendem a ser de maior gravidade quando os dados utilizados no ato discriminatório se tratam de dados sensíveis, tais como os apontados pelo art. 5ํ, II, da LGPD: “origem racial ou étnica, convicção religiosa, opinião política, filiação a sindicato ou a organização de caráter religioso, filosófico ou político, dado referente à saúde ou à vida sexual, dado genético ou biométrico". ${ }^{32}$

Além dos exemplos citados, pode-se falar ainda em mecanismos de bloqueio de conteúdo indesejado e, igualmente, no chamado "policiamento preditivo", que se trata de uma forma de influência por meio de algoritmos preditivos na ação das autoridades públicas em planejamento e implantação de operações, na medida em que há avaliação de dados pessoais em banco de dados públicos (assim como perfis de vítimas, localidades e situações específicas). Tal ferramenta também é capaz de prevenir a ação criminosa do infrator de forma indireta, influenciando seu comportamento por meio da dissuasão. ${ }^{33}$

O fenômeno de acesso fragmentado à informação também contribui para uma alteração na forma com que o usuário percebe o mundo on-line e off-line, na medida em que, de certa forma, plataformas de pesquisa e notícias o impedem de ter acesso livre à informação, isto é, sem que seja direcionado inconscientemente

30 HOFFMANN-RIEM, Wolfgang. Teoria geral do direito digital: transformação digital: desafios para o Direito. Rio de Janeiro: Forense, 2021, p. 63-65.

31 BOFF, Salete Oro; FORTES, Vinicius Borges; FREITAS, Cinthia Obladen de Almendra. Proteção de dados e privacidade: do direito às novas tecnologias na sociedade da informação. Rio de Janeiro: Lumen Juris, 2018, p. 167-170.

32 BRASIL. Lei no 13.709, de 14 de agosto de 2018. Lei Geral de Proteção de Dados. Disponível em: http:// www.planalto.gov.br/ccivil_03/_ato2015-2018/2018/lei/L13709.htm. Acesso em: 28 dez. 2020.

33 HOFFMANN-RIEM, Wolfgang. Teoria geral do direito digital: transformação digital: desafios para o Direito. Rio de Janeiro: Forense, 2021, p. 66. 
pelo algoritmo do sistema a determinada informação que condiz mais com seu perfil. Isso ocorre em razão da formação de bolhas informacionais que constroem um universo de informações exclusivas ao usuário (nutrindo o usuário conforme seus interesses e gostos particulares). Segundo Boff, Fortes e Freitas, as bolhas são, em resumo, apresentadas através de três dinâmicas: i) a bolha agrupa usuários com interesses comuns, sendo afastada de bolhas e agrupamentos diferentes; ii) bolhas são invisíveis, não sendo possível ao usuário escolher quais os critérios utilizados na busca de informação, mas que, paradoxalmente, são percebidas pelo mesmo como verdadeiras e imparciais; iii) não cabe ao usuário escolher não entrar na bolha, visto que, traçado seu perfil, os serviços serão automaticamente colocados à disposição do usuário. ${ }^{34}$

Os excessos de direcionamentos personalizados com base no comportamento do usuário podem gerar sentimentos e respostas negativas, fazendo com que as pessoas percebam certa perda do poder de liberdade de escolha, controle e até mesmo propriedade. ${ }^{35}$ Por outro lado, não se pode ignorar que o uso de novas tecnologias, neste sentido, abarca, sem dúvidas, novas oportunidades para o mercado e a sociedade; todavia, também novos riscos: o tratamento de pessoas como objetos de controle inconsciente (digital unconscious) põe em risco princípios fundamentais do Estado de Direito, inclusive, e em particular, a autonomia e liberdade de autodeterminação, considerando a possibilidade de influência de algoritmos na construção individual e social da sociedade. Mais: "riscos de proteção e manipulação jurídica também existem no uso da seleção e controle digital para atos governamentais". ${ }^{36}$

Infrações à liberdade digital, ao contrário da física, não provocam danos no corpo físico das pessoas, mas ao virtual, que igualmente deve ser objeto de proteção constitucional; no entanto, os riscos à liberdade digital são paradoxalmente invisíveis: quão mais próximos estamos do dano, menos visível ele é. ${ }^{37} 0$ direito ao livre desenvolvimento da personalidade, fundamento da LGPD (art. $2^{\circ}$, VII), é desafiado por práticas de behavioral targeting e profiling que entendem o comportamento do usuário e efetivamente são capazes de direcioná-lo para determinados fins comerciais e, igualmente, eleitorais e políticos. Segundo Rodotà,

34 BOFF, Salete Oro; FORTES, Vinicius Borges; FREITAS, Cinthia Obladen de Almendra. Proteção de dados e privacidade: do direito às novas tecnologias na sociedade da informação. Rio de Janeiro: Lumen Juris, 2018, p. 156-159.

35 BOERMAN, Sophie C.; KRUIKEMEIER, Sanne; BORGESIUS, Frederik J. Zuiderveen. Online Behavioral Advertising: A Literature Review and Research Agenda. Journal of Advertising, v. 46, n. 3, 2017, p. 367. Disponivel em: https://www.tandfonline.com/doi/full/10.1080/00913367.2017.1339368. Acesso em: 05 jan. 2021.

36 HOFFMANN-RIEM, Wolfgang. Teoria geral do direito digital: transformação digital: desafios para o Direito. Rio de Janeiro: Forense, 2021, p. 71-72.

37 BECK, Ulrich. Metamorfose do mundo: novos conceitos para uma nova realidade. Tradução de Maria Luiza X. de A. Borges. Rio de Janeiro: Zahar, 2018, p.185. 
garantias constitucionais devem igualmente estender-se sobre o mundo digital, de forma a proteger o poder de escolha dos indivíduos em rede, lembrando que a “a construção da personalidade requer a liberação de condicionamentos que podem distorcer o seu processo formativo". ${ }^{38}$ A dinâmica de controle, in casu, conclui-se como paradoxal: excessivo controle comportamental digital conduz, logicamente, o usuário à perda da noção de liberdade e do exercício do controle sobre as próprias decisões, levando a um descontrole na formação de suas vontades ou, de outra forma, um "controle guiado" pelo algoritmo.

\section{A (re)afirmação do direito ao livre desenvolvimento da personalidade frente ao controle comportamental e riscos à liberdade digital}

A proteção conferida ao livre desenvolvimento da personalidade é relativamente recente e ganhou força com a Declaração Universal de Direitos Humanos ao dispor no art. 22 que: "Todo o homem, como membro da sociedade, tem direito à segurança social e à realização, pelo esforço nacional, pela cooperação internacional e de acordo com a organização e recursos de cada Estado, dos direitos econômicos, sociais e culturais indispensáveis à sua dignidade e ao livre desenvolvimento de sua personalidade". ${ }^{39}$ A Declaração Universal dos Direitos Humanos ao dar voz ao livre desenvolvimento da personalidade influenciou diversas constituições que ressignificaram a proteção à própria condição humana e sua dignidade.

Neste cenário, a Constituição de Portugal previu no art. 26, inciso 1, ao tratar de outros direitos pessoais que: “A todos são reconhecidos os direitos à identidade pessoal, ao desenvolvimento da personalidade, à capacidade civil, à cidadania, ao bom nome e reputação, à imagem, à palavra, à reserva da intimidade da vida privada e familiar e à proteção legal contra quaisquer formas de discriminação". ${ }^{40}$ Por sua vez, a Lei Fundamental da República Federal da Alemanha, dentre os direitos de liberdade, prevê em seu artigo $2^{\circ}$, inciso I que “Todos têm direito ao livre desenvolvimento da personalidade, contanto que não lesem os direitos de terceiros e não atentem contra a ordem constitucional e os bons costumes" ${ }^{41}$ A Constituição

38 RODOTÀ, Stefano. A vida na sociedade da vigilância: privacidade hoje. Rio de Janeiro: Renovar, 2008, p. 117.

39 ORGANIZAÇÃO DAS NAÇÕES UNIDAS (ONU). Declaração Universal dos Direitos Humanos. Promulgada em 10 de dezembro de 1948. Disponível em: https://www.unicef.org/brazil/declaracao-universal-dos-direitoshumanos. Acesso em: 13 jan. 2021.

40 PORTUGAL. Assembleia da República. Constituição da República Portuguesa. Disponível em: https:// www.igac.gov.pt/documents/20178/358682/Constitui\%C3\%A7\%C3\%A3o+da+Rep\%C3\%BAblica+Portug uesa.pdf/75cbb3ef-b379-43a3-af8c-78ff82b1868f. Acesso em: 13 jan. 2021.

41 ALEMANHA. Lei Fundamental da República Federal. Disponível em: https://www.btg-bestellservice.de/ pdf/80208000.pdf. Acesso em: 13 jan. 2021. 
italiana prevê, em seu art. 2ํㅜ que “a República reconhece e garante os direitos invioláveis do homem, seja como indivíduo, seja nas formações sociais nas quais se desenvolve sua personalidade". ${ }^{42} \mathrm{Na}$ Constituição brasileira, embora não esteja expressamente indicado o direito ao livre desenvolvimento da personalidade, o reconhecimento da dignidade humana, da liberdade e da autonomia como princípios fundantes pressupõem o exercício da liberdade de escolhas existenciais, do direito à imagem, à privacidade e também à proteção de dados pessoais.

No Código Civil brasileiro de 2002 há um capítulo específico para tratar dos direitos de personalidade que estão previstos do art. 11 até o art. 21 com clara indicação de que são "intransmissíveis e irrenunciáveis, não podendo o seu exercício sofrer limitação voluntária”, exceto nos casos previstas em lei. Os direitos de personalidade são muito bem sintetizados por Schreiber ao classificá-los como sendo o "direito ao corpo, direito ao nome, direito à honra, direito à imagem e direito à privacidade". ${ }^{43}$ Freire e Sales complementam que os direitos de personalidade podem ser definidos como o "conjunto de caracteres próprios da pessoa e são direitos inerentes à própria existência”, como a defesa do que lhe é próprio que é a vida, a liberdade, a honra, a identidade, a privacidade e seus bens e valores interiores. ${ }^{44}$

Considerando que a pessoa humana é um ser social que "vive em sociedade integrada dentro de uma comunidade de personalidades", Szaniawski observa que a ordem jurídica deve "tornar possível a cada ser humano realizar sua tarefa ética, seu desenvolvimento criador, sua evolução pessoal e espiritual" e garantir para cada ser humano que ele seja sujeito de direito com a devida "autonomia de vontade em suas relações sociais" e a valorização da dignidade. ${ }^{45}$

Pais de Vasconcelos ao tratar dos direitos da personalidade compreende que “a personalidade é a qualidade de ser pessoa. Esta qualidade tem uma relevância jurídica crucial. Todo o Direito é construído a partir dela e a seu propósito". Cada pessoa humana é única e irrepetível. O autor complementa que "não há Direito sem pessoas, sem pessoas humanas, de carne e osso, com amor e ódio, alegria e tristeza, prazer e dor, bondade e maldade, solidez e fragilidade, concepção e morte". ${ }^{46}$

\footnotetext{
42 RODOTÀ, Stefano. A vida na sociedade da vigilância: privacidade hoje. Rio de Janeiro: Renovar, $2008, \mathrm{p}$. 116.

43 SCHREIBER, Anderson. Direito da Personalidade. 3. ed., rev. e atual. Rio de Janeiro: Atlas, 2014, p. 15.

44 FREIRE, Geovana Maria Cartaxo de Arruda; SALES, Tainah Simões. Os direitos à identidade digital e ao acesso à internet como instrumento de concretização dos objetivos do desenvolvimento do milênio e da democracia. Justiça do Direito, v. 29, n. 3, p. 563-686, set./dez. 2015, p. 568.

45 SZANIAWSKI, Elimar. Direitos de personalidade e sua tutela. 2. ed. São Paulo: Revista dos Tribunais, 2005, p. 115-116.

46 PAIS DE VASCONCELOS, Pedro. Direito de personalidade. Coimbra: Almedina, 2006, p. 47.
} 
Portanto, direitos de personalidade são "próprios da pessoa em si, ou seja, originários do homem, com o seu nascimento, e aqueles referentes à projeção dos direitos de ordem moral e social do homem nas relações exteriores". O que é tutelado "é o valor da pessoa, sem limites, salvo aqueles postos no seu interesse e no interesse de outras pessoas humanas". O ser humano tem a garantia de poder fazer as "escolhas axiológicas que o identificam não só como pessoa humana, mas também que Ihe instituem sua singularidade vital". Dito de outro modo, o livre desenvolvimento da personalidade confere ao ser humano a garantia de autodeterminação "sobre si mesmo (liberdades individuais psíquicas)", bem como a garantia de liberdade de consciência, direito à integridade intelectual e moral, livre manifestação do pensamento, livre desenvolvimento espiritual e intelectual, liberdade de crença, liberdade política, identidade pessoal, familiar e social e de divertimento. Também é entendido como a liberdade pública pessoal que se manifesta "na segurança do próprio corpo físico (integridade física, liberdade de ir e vir)" e "como condição da existência coletiva, da extensão dos interesses particulares de um sujeito à esfera de outrem com interesses igualmente dignos de tutela". ${ }^{47}$

Sistemas programados para induzir condutas violam o núcleo central do direito ao livre desenvolvimento da personalidade e subtraem algo da dignidade, como a faculdade do ser humano de se definir como pessoa e de se tornar o que intimamente planejou.

Os desafios jurídicos, éticos e sociológicos decorrentes do desenvolvimento e uso desse tipo de tecnologia de controle comportamental são produto do que o sociólogo Ulrich Beck denomina de segunda modernidade: na primeira, impera a metafísica da reprodução, onde o futuro não perde conexões básicas com o passado e a sociedade é capaz de prever e colonizar o futuro; no entanto, na segunda, a modernidade acaba por romper com a continuidade do passado, visto que velhos preceitos (jurídicos-éticos-sociais) não mais aplicam-se de forma integral diante da nova realidade tecnológica que emerge. ${ }^{48}$

No entanto, é possível considerar a extensão de princípios e normas jurídicas como válidos à proteção da personalidade do indivíduo dentro do meio digital: a virtualização dos corpos, como bem aponta Pierre Lévy, é uma nova etapa de autocriação - através da técnica - que sustenta a espécie humana, sendo uma projeção, vetorização, multiplicação ou mesmo heterogenia do corpo humano. ${ }^{49}$ Sobre corpo humano se assenta o pressuposto de dignidade humana, fundamento da ordem constitucional brasileira (art. 1ํㅡ, III, CF/88), sendo-Ihe assegurados direitos

47 ARAÚJO, Maria Angélica Benetti. A disciplina dos direitos de personalidade no Direito Português. Revista de Direito Privado, v. 45, p. 41-68, Jan./Mar, 2011, p. 43.

48 BECK, Ulrich. Metamorfose do mundo: novos conceitos para uma nova realidade. Tradução de Maria Luiza X. de A. Borges. Rio de Janeiro: Zahar, 2018, p. 72.

49 LÉVY, Pierre. O que é virtual? 2. ed. Tradução de Paulo Neves. São Paulo: Editora 34, 2011, p. 27-33. 
humanos e garantias fundamentais arroladas no art. 5oda Constituição brasileira: o corpo virtual é extensão do corpo físico (inclusive sendo capaz de provocar efeitos neste), logo estende-se o escopo protetivo constitucional sobre o mesmo, a fim de garantir efetiva dignidade e eficácia sobre os direitos fundamentais. Tem-se, neste sentido, uma (re)construção de direitos de liberdade e defesa da personalidade, transformando-se "do segredo das comunicações na internet à extensão da promessa da Magna Charta - não te tocaremos - do corpo físico ao corpo eletrônico". 50

Neste aspecto, normas de proteção de direito de liberdade, igualdade e, inclusive, livre desenvolvimento da personalidade abrangem infraestruturas digitais, servindo de parâmetro para avaliação jurídica das consequências da seleção e controle algorítmico do comportamento, garantindo-se o exercício do direito de liberdade e formação do pensamento a sem influência, direta ou indireta, de direcionamentos comportamentais ou decisões automáticas fundadas em "metainformações" no processo de profiling. A eficácia horizontal dos direitos fundamentais também é importante neste sentido, visto que atores privados podem consideravelmente interferir na esfera de garantais constitucionais dos cidadãos, uma vez que cada vez mais empresas privadas prestam serviços básicos, tendo o poder de interferir, através de extensa coleta de dados pessoais, na formação da opinião política, restrição e geração de oportunidades, participação social e, inclusive, em tarefas mais cotidianas da vida. ${ }^{51}$

Ainda assim, segundo Ingo Wolfgang Sarlet, tais circunstâncias acabam por ensejar, igualmente, “a criação de novos mecanismos para a proteção da dignidade humana e dos direitos de personalidade por um lado [...] e, por outro, dos princípios do estado de direito, da democracia e das correlatas liberdades comunicativas" ${ }^{52}$ Neste aspecto, Wolfgang Hoffmann-Riem aponta que o risco digital que o controle comportamental representa para o direito ao livre desenvolvimento da personalidade pode ser elidido através de uma forte tutela do direito à autodeterminação informativa, ${ }^{53}$ que se faz presente em mecanismos de defesa constantes em recentes legislações sobre proteção de dados, como a GDPR europeia e a Lei Geral de Proteção de Dados brasileira, edificada com fundamento na autodeterminação

50 RODOTÀ, Stefano. A vida na sociedade da vigilância: privacidade hoje. Rio de Janeiro: Renovar, 2008, p. 272.

51 HOFFMANN-RIEM, Wolfgang. Teoria geral do direito digital: transformação digital: desafios para o Direito. Rio de Janeiro: Forense, 2021, p. 42-46.

52 SARLET, I. W. Proteção da personalidade no ambiente digital: uma análise à luz do caso do assim chamado Direito ao Esquecimento no Brasil. Espaço Jurídico Journal of Law [EJJL], v. 19, n. 2, p. 491-530, 16 ago. 2018. Disponível em: https://portalperiodicos.unoesc.edu.br/espacojuridico/article/view/17557. Acesso em: 16 jan. 2021.

53 HOFFMANN-RIEM, Wolfgang. Teoria geral do direito digital: transformação digital: desafios para o Direito. Rio de Janeiro: Forense, 2021, p. 46. 
informativa (art. 2으. II), o livre desenvolvimento da personalidade e a dignidade da pessoa humana (art. $\left.2^{\circ}, \mathrm{VII}\right)$.

Ademais, reforça-se a analogia de Beck acerca dos ditames de Tocqueville sobre o "espírito humano": "se a modernidade rompe com a continuidade, visto que o passado cessa de lançar luz sobre o futuro, o espírito humano fica preso na escuridão". ${ }^{54} \mathrm{O}$ desenvolvimento das novas tecnologias avança consideravelmente mais rápido do que a capacidade de reflexão humana sobre as consequências jurídicas e éticas de suas aplicações, levantando questões maiores do que os propósitos do uso da técnica: desenvolver veículos e armas autônomas para substituir combatentes no campo de batalha? ${ }^{55}$ Criar cidades digitais, como em Barcelona, na Espanha, ou plataformas de participação popular conduzidas por meio de sistemas de Inteligência Artificial, como instalado em Reykjavik, na Islândia? ${ }^{56}$ Valer-se de processos de profiling e behavioral targeting para induzir, manipular ou influenciar o comportamento humano no exercício da liberdade ou do livre desenvolvimento da personalidade? Os fins para que são utilizadas tecnologias são relevantes, considerando que vivemos em constante relações de poder - em que igualmente não é possível simplesmente reduzir o usuário à condição de vítima, na medida em que também exercem poder ao curtir, postar, compartilhar e interagir on-line. Desta forma, "qual a melhor maneira de exercer a liberdade em uma sociedade tecnológica apresenta-se como um dos mais importantes desafios da contemporaneidade" ${ }^{57}$ Neste aspecto, para além do campo do Direito, não há como escapar de diálogos com a Filosofia e a Ética.

Recorre-se, então, a Heidegger em seus escritos ao questionar a técnica, refletindo que o ser humano, no esforço de conduzir uma relação com a técnica, chega tarde demais para aquilo que a técnica essencializa, o que o coloca em perigo por não mais encontrar a si mesmo, ou seja: quando a vida é governada pela técnica o ser humano pode não mais encontrar a sua essência e tudo o que o define como ser humano. Entretanto, alerta que não é a técnica o perigo ou que ela seja demoníaca, pelo contrário, na técnica existe o mistério. Para o autor, a ameaça não vem das máquinas e dos aparelhos da técnica que podem causar a morte, mas a verdadeira ameaça já atacou o ser humano na sua essência quando o

54 BECK, Ulrich. Metamorfose do mundo: novos conceitos para uma nova realidade. Tradução de Maria Luiza X. de A. Borges. Rio de Janeiro: Zahar, 2018, p. 72.

55 HUPFFER, Haide Maria; PETRY, Gabriel Cemin. A (im)possibilidade do uso de Lethal Autonomous Weapon System frente ao direito internacional humanitário e a ética. Revista Brasileira de Estudos de Defesa. v. 6, n. 2, p. 125-153, jul./dez. 2019, p. 125-129. Disponível em: https://rbed.abedef.org/rbed/article/ view/75153. Acesso em: 22 jan. 2020.

56 MOROZOV, Evgeny; BRIA, Francesca. A Cidade Inteligente: tecnologias urbanas e democracia. Tradução de Humberto do Amaral. São Paulo: Ubu, 2019, p. 96 e 176.

57 ROSA, Fábio Medeiros da; CHEVITARESE, Leandro. Vigilância e relações de poder nas redes sociais: questões éticas na sociedade contemporânea. ORGANICOMP, ano 14, n. 27, p. 59-69, 2ํsem. 2017, p. 67. 
“homem se encontra impedido de perceber o apelo de uma verdade mais originária" e abandona a sua livre essência. Por isso, Heidegger convoca o ser humano a questionar a técnica, a ver o perigo da técnica, pois ao olhar para o perigo ele se questiona e reflete sobre a essência da técnica, e este questionar para o filósofo alemão "é a devoção do pensamento". 58

Ao questionar a técnica, Heidegger empreendeu uma caminhada para mostrar que a questão do ser deve ser a verdadeira e única tarefa dos pensadores e que a vida humana não pode ser compreendida com uma postura teórica objetivadora. O caminho do pensamento sobre o ser necessita da clareira, que para Heidegger pode ser percorrido, se a pergunta pelo sentido do ser for corretamente posta.

As contribuições de Heidegger instigam a questionar se o livre desenvolvimento da personalidade não está sendo diariamente ameaçado pelas estruturas midiáticas da sociedade da informação. Assim, questiona-se: até que ponto os sistemas de vigilância estão sendo moldados ao controle dos seus criadores para realizarem uma coletivização de adequação de comportamentos e produção de subjetividade? Restará alguma coisa de substancial da condição humana e da personalidade que define cada ser humano se todos os passos virtuais e físicos são acompanhados, controlados, vigiados, moldados pelos governos, organizações formais, empresas, amigos virtuais, corporações nacionais e internacionais, empresas de marketing e hackers? Para ingressar no "maravilhoso" mundo digital os próprios sujeitos se subordinam à biopolítica da sociedade de controle e na simplificação perigosa da liberdade de expressão e da personalidade.

Neste sentido, Hans Jonas, discípulo de Heidegger, atenta justamente a hipótese de que os velhos imperativos éticos não mais encontram total guarida no futuro tecnológico, de forma que se faz necessária uma ética do futuro pautada no princípio responsabilidade. In casu, sobre a natureza modificada do agir humano, atenta Jonas quanto aos benefícios e perigos éticos do controle comportamental: salvar pessoas portadoras de deficiências mentais e de sintomas dolorosos parece ser algo positivo e benéfico; todavia “uma certa transição leva do alívio do paciente - um objeto em total consonância com a tradição médica - a aliviar a sociedade da inconveniência de tratamentos individuais difíceis entre seus membros". Para o filósofo alemão, problemas persistentes na sociedade de massas acabam por tornar este tipo de prática sedutora para fins não medicinais, isto é, para manipulação social, de forma que quando contornado o caminho humano, para a resolução de problemas humanos, "substituindo por curto-circuito de um mecanismo impessoal, subtraímos algo da dignidade dos indivíduos e damos mais um passo à frente no

58 HEIDEGGER, Martin. A questão da técnica. Scientiæ Zudia, São Paulo, v. 5, n. 3, p. 375-98, 2007, p. 386-396. Disponível em: http://www.scientiaestudia.org.br/revista/PDF/05_03_05.pdf. Acesso em: 15 jan. 2021. 
caminho que nos conduz de sujeitos responsáveis a sistemas programados de conduta". 59

Como observado, com o avanço da sociedade digitalmente intermediada por algoritmos e pela Internet das Coisas, o valor dos dados pessoais passou a ser uma moeda de troca na economia do conhecimento, o que tornou ainda mais complexo o desafio de ser completamente anônimo, o que vem causando a erosão gradual dos direitos de personalidade. 0 risco de identificação dos dados pessoais processados se tornou relevante a ponto de enfraquecer os direitos de personalidade dos indivíduos. A melhor legislação de proteção de dados não oferece proteção integral à privacidade individual, pois uma vez que os dados forem analisados e as informações sobre as pessoas forem adquiridas e compartilhadas, nada garante que os dados sejam excluídos quando o indivíduo pleitear o direito ao esquecimento ou o direito a que seus dados sejam apagados. Pelas inúmeras interações diárias, em diferentes ambientes informacionais, acrescidos com as interações possibilitadas pela Internet das Coisas, outro grande desafio é identificar com quem estão os dados pessoais: com o fabricante do dispositivo ou com os sensores? Com os desenvolvedores de software e aplicativos? Com os provedores de infraestrutura e/ou negócios da análise de dados? Com o governo? ${ }^{60}$

A Inteligência Artificial com o desenvolvimento de complexos sistemas de algoritmos digitais terá capacidade de predizer qualquer cenário de forma completamente determinista. Qualquer objeto ligado à rede de internet poderá mapear e vigiar todos os passos do ser humano, seu código genético, suas preferências, hábitos, expressões faciais, redes sociais, consultadas na internet, familiares, aptidões, perfil psicológico, perfil genético, relações, opiniões, preferência política, predições sobre enfermidades e habilidades de potenciais filhos e o sequenciamento do genoma de todos os habitantes de determinada localidade. Frente à possibilidade de coletar grandes volumes de dados e de desenhar sofisticados sistemas de análise e mineração de dados, o uso inadequado da Inteligência Artificial pode expor o ser humano a novas situações de vulnerabilidade e violar direitos da personalidade. Qualquer ação que o ser humano realiza poderá ser objeto de recopilação e análise. A Inteligência Artificial, entendida como Big Data, com a "humanidade datificada" poderá prever com perfeição o comportamento imediato de qualquer pessoa, mesmo quando ela não estiver consciente da sua personalidade ou de suas decisões. ${ }^{61}$

59 JONAS, Hans. O princípio responsabilidade: ensaio de uma ética para civilização tecnológica. Tradução original de Marijane Lisboa, Luiz Barros Montez. Rio de Janeiro: Contraponto: Ed. PUC-Rio, 2006.

60 KAUFFMAN, Marcos E.; NEGRI, Marcelo. New technologies and data ownership: wearables and the erosion of personality rights. Revista de Direitos Sociais e Políticas Públicas (Unifafibe), v. 6, n. 1, p. 512-538, 2018, p. 528-533. Disponível em: http://www.unifafibe.com.br/revista/index.php/direitos-sociaispoliticas-pub/issue/view/25. Acesso em: 14 jan. 2021.

61 BARONI, Manuel Jesús López. Las narrativas de la inteligencia artificial. Revista de Bioetica \& Derecho, Barcelona, v. 46, p. 5-28, jul. 2019, p. 10-12. Disponível em: https://revistes.ub.edu/index.php/RBD/ article/view/27280/29232. Acesso em: 12 jan. 2021 
Os algoritmos modificam a percepção do mundo e também atuam sobre o comportamento social influenciando a sociedade na tomada de decisões. A vigilância “por cima da pele" já é realidade e os "Estados podem vigiar não somente o que as pessoas fazem, como também o que sentem ou pensam, através de tecnologia que monitore sinais biométricos como a pressão sanguínea e o ritmo cardíaco". Para desenvolver a vigilância, a premissa é a de que "os estados emocionais e anímicos são meros fenômenos biológicos que se correlacionam com sinais biométricos". Com o desenvolvimento de algoritmos é possível em tempo real saber se uma pessoa ao ler uma notícia, ler comentários ou olhar fotos no Facebook, ver um vídeo e assistir TV se ela está irritada ou ansiosa, feliz ou triste e assim enviar propagandas, notícias e novas informações. Para além disso, Harari complementa que “o desenvolvimento mais importante do século XXI é a habilidade de 'hackear' os seres humanos, ir por baixo da pele, coletar dados biométricos, analisá-los e entender as pessoas melhor do que entendem a si mesmas". ${ }^{62}$

Estes são exemplos que não esgotam as interferências das novas tecnologias na sociedade, especialmente no que toca ao controle de comportamento humano por meio de algoritmos. Neste aspecto, repisa-se que paira paradoxal dinâmica de controle sobre o comportamento: $l$ ) através da coleta e análise de dados pessoais do usuário, é possível não somente direcionar seus passos com base em seu comportamento, mas, prevê-lo e influenciá-lo por meio de algoritmos, de forma que o detentor da informação exerce controle sobre o titular dos dados; ii) através do controle comportamental digital, o titular dos dados perde a noção de liberdade e do exercício do controle sobre as próprias decisões, levando a um descontrole na formação de suas vontades ou, de outra forma, um “controle guiado" pelo algoritmo.

\section{Conclusão}

As novas tecnologias, frutos da técnica humana, estão por toda parte, atuando nos mais diversos processos e campos da sociedade moderna, abarcando tanto novas oportunidades quanto novos riscos à sociedade informacional. Do processo de digitalização das coisas, o produto de dados pessoais digitais se destaca, sendo comparado comumente ao novo petróleo da modernidade, considerando a elevada gama de possibilidades de mercado, uma vez que é multilateral e capaz de relacionar-se com áreas distintas; a quantidade de produtos e atuações comerciais

62 APROXIMA-SE a era da vigilância subcutânea, adverte Yuval Noah Harari. Entrevista concedida à BBC e publicada na Revista IHU ONLINE, 20 maio 2020. Disponível em: http://www.ihu.unisinos.br/78noticias/599123-aproxima-se-a-era-da-vigilancia-subcutanea-adverte-yuval-noah-harari. Acesso em: 16 jan. 2021. 
derivadas de dados pessoais; assim como a alta rentabilidade e vantagens de controle e poder a serem adquiridas pelos detentores da informação.

Dentre estas vantagens destaca-se a coleta, uso e venda de dados pessoais de consumidores usuários de aplicativos, mecanismos de busca em rede, aparelhos telefônicos, redes sociais, entre outros, para processos de profiling e behavioral targeting, primeiro traçando um perfil do usuário, com base nos dados coletados, e, após, direcionando seu comportamento, por meio de anúncios personalizados, induzindo o usuário a realizar determinada ação, que pode estar voltada tanto para a indução de comportamento do consumidor a compra de determinado produto quanto a do eleitor em determinada corrida eleitoral para que simpatize com determinado candidato ou ideal político. Mais: através de práticas de profiling também se faz possível agrupar usuários que possuem interesses comuns nas chamadas "bolhas informacionais", separando-as das demais e nutrindo os usuários com informações parciais, fragmentadas e selecionadas por algoritmos conforme os interesses destacados no perfil, podendo, fora os entraves relacionados ao acesso à informação, a formação de perfis por meio de algoritmos levar a práticas discriminatórias quanto a grupos de minorias selecionados.

Levantam-se questões acerca da harmonia do uso e desenvolvimento destas tecnologias com o direito e a ética, o que se faz desafiador, considerando que a modernidade não mais consegue buscar apoio em respostas passadas, uma vez que problemas como o controle comportamental digital não antes foram enfrentados e sequer imaginados. Além do frontal ataque à garantia constitucional de liberdade (digital), também é possível ver danos reflexos no direito à informação, igualdade, privacidade e, em especial, ao direito de livre desenvolvimento da personalidade, que está intimamente atrelado à dignidade humana no ato da formação da personalidade e escolhas sobre o corpo, o qual resta em xeque com o emprego de tecnologias voltadas ao direcionamento comportamental humano.

A garantia de livre desenvolvimento da personalidade faz-se presente em inúmeros documentos e Constituições internacionais, como, no caso da Declaração Universal de Direitos do Homem, e, igualmente, nas Constituições da Alemanha, Itália e Portugal, por exemplo, protegendo o direito do indivíduo de estar livre para construir sua identidade, formar sua personalidade e tomar decisões sobre o próprio corpo. A Carta Magna brasileira, embora não mencione expressamente tal garantia, está fundada sob o princípio de dignidade da pessoa humana, guarnecendo o indivíduo de direitos fundamentais de liberdade, igualdade, privacidade, livre manifestação do pensamento e, entre outros, informação, bem como a proteção do indivíduo e seu corpo está garantida em legislações infraconstitucionais, como o Código Civil de 2002. 
O direito ao livre desenvolvimento da personalidade, neste contexto, garante a liberdade física e psíquica à pessoa humana e seu corpo, o qual, por força das transformações da digitalização do mundo, é virtualizado, sendo uma heterogenia do corpo, ou seja, uma extensão do corpo físico que igualmente demanda tutela jurídica. Neste aspecto, a defesa das garantias fundamentais no contexto de controle comportamental pode dar-se através de uma (re)afirmação do direito ao livre desenvolvimento da personalidade: $l$ ) aplicando-se princípios e direitos fundamentais existentes de forma horizontal, não somente servindo de freios às arbitrariedades estatais, mas também, às práticas arbitrárias de empresas e organizações privadas, bem como interpretando-se de forma extensiva os direitos fundamentais para utilização de técnicas de controle comportamental por meio de algoritmos, criando parâmetros de avaliação jurídica das consequências na aplicação de tais tecnologias, de forma a fortalecer a liberdade de decisão do indivíduo e seu controle às formas de tratamento de seus dados pessoais; ii) a criação de novos mecanismos legais de defesa da dignidade humana e livre desenvolvimento da personalidade, bem como o fortalecimento de legislações específicas acerca da regulação do direito à autodeterminação informativa, como é o caso da GDPR europeia e da LGPD brasileira, que é capaz de neutralizar os riscos à liberdade digital decorrentes da prática de controle comportamental por meio de algoritmos.

O presente trabalho apresenta apenas incipientes resoluções e provocações acerca da implementação de tais tecnologias no direito, não esgotando a temática e sua monumental variedade de interrogações, de forma que persistem questionamentos jurídicos-éticos-sociais sobre o desenvolvimento e aplicação de técnicas de direcionamento e controle comportamental. Ainda assim, faz-se pertinente atentar, com base em Heidegger, que a vida não pode ser governada tão somente pelos parâmetros e promessas da técnica, sob pena de abandono das razões de humanidade, bem como, fundado em Hans Jonas, ao avanço tecnológico não é lícito apostas totais sobre a vida e a dignidade humana, de forma que seu desenvolvimento deve pautar-se essencialmente na responsabilidade e no respeito às gerações que herdarão as consequências do presente.

\section{Referências}

ALEMANHA. Lei Fundamental da República Federal. Disponível em: https://www.btg-bestellservice. de/pdf/80208000.pdf. Acesso em: 13 jan. 2021.

APROXIMA-SE a era da vigilância subcutânea, adverte Yuval Noah Harari. Entrevista concedida à BBC e publicada na Revista IHU ONLINE, 20 maio 2020. Disponivel em: http://www.ihu.unisinos. $\mathrm{br} / 78$-noticias/599123-aproxima-se-a-era-da-vigilancia-subcutanea-adverte-yuval-noah-harari. Acesso em: 16 jan. 2021.

ARAÚJO, Maria Angélica Benetti. A disciplina dos direitos de personalidade no Direito Português. Revista de Direito Privado, v. 45, p. 41-68, Jan./Mar, 2011. 
ARGENTINA. Protección de los datos personales. Ley 25.326/2020. Promulgada parcialmente en octubre 30 de 2000. Disponível em: https://www.oas.org/juridico/PDFs/arg_ley25326.pdf. Acesso em: 18 dez. 2020.

BARONI, Manuel Jesús López. Las narrativas de la inteligencia artificial. Revista de Bioetica \& Derecho, Barcelona, v. 46, p. 5-28, jul. 2019, p. 10-12. Disponivel em: https://revistes.ub.edu/ index.php/RBD/article/view/27280/29232. Acesso em: 12 jan. 2021.

BECK, Ulrich. Metamorfose do mundo: novos conceitos para uma nova realidade. Tradução de Maria Luiza X. de A. Borges. Rio de Janeiro: Zahar, 2018.

BOEING, D. H. A.; MORAIS DA ROSA, Alexandre. Ensinando um robô a julgar. pragmática, discricionariedade, heurísticas e vieses no uso de aprendizado de máquinas no judiciário. Florianópolis: Emais Academia, 2020.

BOERMAN, Sophie C.; KRUIKEMEIER, Sanne; BORGESIUS, Frederik J. Zuiderveen. Online Behavioral Advertising: A Literature Review and Research Agenda. Journal of Advertising, v. 46, n. 3, p. 363376, 2017. Disponivel em: https://www.tandfonline.com/doi/full/10.1080/00913367.2017.1 339368. Acesso em: 05 jan. 2021.

BOFF, Salete Oro; FORTES, Vinicius Borges. FREITAS, Cinthia Obladen de Almendra. Proteção de dados e privacidade: do direito às novas tecnologias na sociedade da informação. Rio de Janeiro: Lumen Juris, 2018.

BRASIL. CONSELHO NACIONAL DE JUSTIÇA. Projetos com Inteligência Artificial no Poder Judiciário. Disponível em: https://paineisanalytics.cnj.jus.br/single/?appid=29d710f78d8f-47be-8af8-a9152545b771\&sheet=b8267e5a-1f1f-41a7-90ff-d7a2f4ed34ea\&lang=ptBR\&opt=ctxmenu,currsel. Acesso em: 06 jan. 2020.

BRASIL. Lei no 13.709, de 14 de agosto de 2018. Lei Geral de Proteção de Dados. Disponível em: http://www.planalto.gov.br/ccivil_03/_ato2015-2018/2018/lei/L13709.htm. Acesso em: 28 dez. 2020.

CHELIGA, Vinicius; TEIXEIRA, Tarcísio. Inteligência Artificial: aspectos jurídicos. Salvador: JusPodivm, 2019.

CHILE. Ley № 19.628 de 18 ag. 1999. Sobre Protección de la vida privada. Disponível em: https://www.leychile.cl/Navegar?idNorma=141599\&buscar=19628. Acesso em: 10 dez. 2020.

EDWARDS, Jim. Apple Has Quietly Started Tracking iPhone Users Again, And It's Tricky To Opt Out, 2012. Disponivel em: https://www.businessinsider.com/ifa-apples-iphone-tracking-inios-6-2012-10. Acesso em: 04 jan. 2021.

FREIRE, Geovana Maria Cartaxo de Arruda; SALES, Tainah Simões. Os direitos à identidade digital e ao acesso à internet como instrumento de concretização dos objetivos do desenvolvimento do milênio e da democracia. Justiça do Direito, v. 29, n. 3, p. 563-686, set./dez. 2015.

HEIDEGGER, Martin. A questão da técnica. Scientiæ Zudia, São Paulo, v. 5, n. 3, p. 375-98, 2007, p. 386-396. Disponivel em: http://www.scientiaestudia.org.br/revista/PDF/05_03_05. pdf. Acesso em: 15 jan. 2021.

HOFFMANN-RIEM, Wolfgang. Teoria geral do direito digital: transformação digital: desafios para o Direito. Rio de Janeiro: Forense, 2021.

HUPFFER, Haide Maria; PETRY, Gabriel Cemin. A (im)possibilidade do uso de Lethal Autonomous Weapon System frente ao direito internacional humanitário e a ética. Revista Brasileira de Estudos de Defesa. v. 6, n. 2, p.125-153, jul./dez. 2019, p. 125-153. Disponivel em: https://rbed.abedef. org/rbed/article/view/75153. Acesso em: 22 jan. 2020. 
JONAS, Hans. O princípio responsabilidade: ensaio de uma ética para civilização tecnológica. Tradução original de Marijane Lisboa, Luiz Barros Montez. Rio de Janeiro: Contraponto: Ed. PUCRio, 2006.

KAUFFMAN, Marcos E.; NEGRI, Marcelo. New technologies and data ownership: wearables and the erosion of personality rights. Revista de Direitos Sociais e Políticas Públicas (Unifafibe), v. 6 , n. 1, p. 512-538, 2018, p. 528-533. Disponivel em: http://www.unifafibe.com.br/revista/index. php/direitos-sociais-politicas-pub/issue/view/25. Acesso em: 14 jan. 2021.

LÉVY, Pierre. O que é virtual? 2. ed. Tradução de Paulo Neves. São Paulo: Editora 34, 2011.

MOROZOV, Evgeny; BRIA, Francesca. A Cidade Inteligente: tecnologias urbanas e democracia. Tradução de Humberto do Amaral. São Paulo: Ubu, 2019.

ORGANIZAÇÃO DAS NAÇÕES UNIDAS (ONU). Declaração Universal dos Direitos Humanos. Promulgada em 10 de dezembro de 1948. Disponível em: https://www.unicef.org/brazil/ declaracao-universal-dos-direitos-humanos. Acesso em: 13 jan. 2021.

PAIS DE VASCONCELOS, Pedro. Direito de personalidade. Coimbra: Almedina, 2006.

PORTUGAL. Assembleia da República. Constituição da República Portuguesa. Disponível em: https://www.igac.gov.pt/documents/20178/358682/Constitui\%C3\%A7\%C3\%A3o+da+Rep\%C3 \%BAblica+Portuguesa.pdf/75cbb3ef-b379-43a3-af8c-78ff82b1868f. Acesso em: 13 jan. 2021.

RODOTÀ, Stefano. A vida na sociedade da vigilância: privacidade hoje. Rio de Janeiro: Renovar, 2008.

ROSA, Fábio Medeiros da; CHEVITARESE, Leandro. Vigilância e relações de poder nas redes sociais: questões éticas na sociedade contemporânea. ORGANICOMP, ano 14, n. 27, p. 59-69, 2 으. 2017.

RUARO, Regina Linden. Privacidade e autodeterminação informativa: obstáculos ao Estado de Vigilância. Arquivo Jurídico, Teresina-PI, v. 2, n. 1, jan./ jun. de 2015, p. 41-60. Disponível em: http://revistas.ufpi.br/index.php/raj. Acesso em: 10 jan. 2021.

SARLET, I. W. Proteção da personalidade no ambiente digital: uma análise à luz do caso do assim chamado Direito ao Esquecimento no Brasil. Espaço Jurídico Journal of Law [EJJL], v. 19, n. 2, p. 491-530, 16 ago. 2018. Disponível em: https://portalperiodicos.unoesc.edu.br/espacojuridico/ article/view/17557. Acesso em: 16 jan. 2021.

SCHREIBER, Anderson. Direito da Personalidade. 3. ed., rev. e atual. Rio de Janeiro: Atlas, 2014.

SZANIAWSKI, Elimar. Direitos de personalidade e sua tutela. 2. ed. São Paulo: Revista dos Tribunais, 2005.

UNIÃO EUROPEIA. Regulamento (UE) 2016/679 do Parlamento Europeu e do Conselho de 27 de abril de 2016. Disponivel em: https://eur-lex.europa.eu/legal-content/PT/TXT/PDF/?uri=CELEX: 32016R0679\&from=pt. Acesso em: 20 dez. 2020.

Informação bibliográfica deste texto, conforme a NBR 6023:2018 da Associação Brasileira de Normas Técnicas (ABNT):

HUPFFER, Haide Maria; PETRY, Gabriel Cemin. (Des)Controle digital de comportamento e a proteção ao livre desenvolvimento da personalidade. International Journal of Digital Law, Belo Horizonte, ano 2, n. 1, p. 111-132, jan./abr. 2021. 